\title{
Photodegradation of Dialkyl 1,3-Dithiolan-2-ylidenemalonates and Some Other Pesticides on Solid Particles
}

\author{
Shin-Shou ChOU*, Eiji TANiguchi and Morifusa Eto \\ Department of Agricultural Chemistry, Kyushu University, \\ Fukuoka 812, Japan \\ Received April 14, 1980
}

\begin{abstract}
On irradiation with UV light the fungicide isoprothiolane (diisopropyl 1,3-dithiolan-2ylidenemalonate) decomposed rapidly on the silica gel surface. The degradation pathways involved dithiolane ring cleavage, ester hydrolysis, decarboxylation, heterocycles formation such as dithietane and trithiolane, and sulfur liberation. The photoproducts confirmed were oxalic acid, dithiolanylidenemalonic acid, dithiolanylideneacetic acid, 2,4-bis[bis(isopropoxycarbonyl) methylene]-1, 3-dithietane, 3, 5-bis [bis(isopropoxy-carbonyl)methylene]-1,2,4-trithiolane and sulfur. The methyl and ethyl homologs of isoprothiolane similarly gave the corresponding photoproducts. The surface area where isoprothiolane was placed appeared to be related closely with the photolysis rate. Isoprothiolane decomposed much more rapidly on sand than on a glass plate. This surface effect was greatly depressed under nitrogen atmosphere. Similar phenomena were observed with some other pesticides, with particularly those containing sulfur atoms in the molecule.
\end{abstract}

The systemic fungicide isoprothiolane (diisopropyl 1,3-dithiolan-2-ylidenemalonate) (I) is effective to control rice blast disease caused by Pyricularia oryzae and rice stem-rot (Helminthosporium sigmoideum). ${ }^{1,2}$ It has also an effect to suppress the population of certain insects, especially, planthoppers. ${ }^{2)}$ In the field, isoprothiolane can be applied to paddy water as well as to foliage. Its unique chemical structure including a dithiolane ring, an exocyclic methylene group, and ester linkages appears interesting for photochemical studies. In a previous short communication, we reported briefly that the transformation of the dithiolane ring into dithietane and trithiolane rings, and the degradation of the ester groups took place on silica gel by irradiation of short

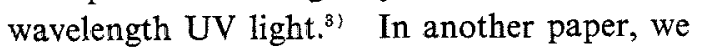
studied the photolysis of isoprothiolane in aqueous media, in which a photosensitizer riboflavin accelerated the photolysis in the presence of oxygen."

This paper deals with the photodegradation of isoprothiolane and its homologs on solid

* Present address: Executive Yuan National Health Administration, Bureau of Drug and Food Inspection, Taipei, Taiwan. particles in detail. Air and the area of surface where the chemicals were deposited were very important factors for the photodegradation. Some other pesticides including benthiocarb, carbaryl, cartap, diazinon, IBP, mepronil, salithion, and thiram were subjected to photodegradation and the surface effect was commonly observed in sulfur containing compounds.

\section{MATERIALS AND METHODS}

Chemicals. Technical isoprothiolane $(96 \%)$ provided from Nihon Noyaku Co. was purified by recrystallization from $n$-hexane, $\mathrm{mp} 57^{\circ} \mathrm{C}$. The authentic standards of 1,3-dithiolan-2-ylidenemalonic acid, 1,3dithiolan-2-ylideneacetic acid, dimethyl 1,3-dithiolan2-ylidenemalonate, and diethyl 1,3-dithiolan-2-ylidenemalonate were gifts from the same company. Methyl dithiolanylideneacetate was prepared by treating the corresponding acid with diazomethane in ether and purified by silica gel TLC and identified by NMR.

Benthiocarb [S-(4-chlorobenzyl) $N, N$-diethylthiolcarbamate, pure], carbaryl(1-naphthyl $N$-methylcarbamate, pure), IBP $(O, O$-diisopropyl $S$-benzyl phosphorothiolate, $99 \%$ ), mepronil (2-methylbenz-3-isopropoxyanilide, pure), and diazinon (diethyl 2isopropyl-4-methyl-6-pyrimidinyl phosphorothionate, technical) were gifts from Kumiai Chemical Co. Cartap [1, 3-bis(carbamoylthio)-2-( $N, N$-dimethyl) aminopro- 
pane hydrochloride, $98 \%$ ] was a gift from Takeda Chemical Ind. Salithion (2-methoxy-4H-1,3,2-benzodioxaphosphorin 2-sulfide, technical) was provided from Sumitomo Chemical Ind. and purified by recrystallization from methanol. Thiram (tetramethylthiuram disulfide) was synthesized by the oxidation of sodium dimethyldithiocarbamate by hydrogen peroxide, purified by recrystallization from ethanol and identified by NMR. Sea sand (Ishizu, extra grade) was soaked in diluted hydrochloric acid, washed with deionized water, dried, and passed through a sieve. All solvents used were redistilled in glass and all other commercial chemicals were of guaranteed reagent grade quality.

Photochemical procedures. Isoprothiolane or its homolog was placed on a silica gel TLC plate as a spot or a streak and irradiated at a $10 \mathrm{~cm}$ distance by a $10 \mathrm{~W}$ Toshiba germicidal lamp emitting mainly $254 \mathrm{~nm}$ UV light. For the quantitative analysis a chromarod was utilized in place of the plate and submitted to a thinchrograph. Photoproducts isolated from TLC plate were again treated with UV on a chromatoplate in order to elucidate the photolysis pathways.

A 100W high pressure mercury lamp emitting UV light in longer wavelength than $300 \mathrm{~nm}$ was also used. Isoprothiolane placed on the chromatoplate was also exposed to sunlight from 9 a.m. to $5 \mathrm{p} . \mathrm{m}$. on fine summer days in Fukuoka.

Another experiments to examine the effect of surface area on the photolysis of pesticides, petri dishes and sand were used as a carrier without cover. A solution dissolving $1 \mathrm{mg}$ of a pesticide in an appropriate solvent was poured into a petri dish $(9.4 \mathrm{~cm}$ in diameter) where sea sand $(7 \mathrm{~g})$ had been spread or not. After the solvent evaporated, the dish was irradiated with the germicidal lamp for a definit time and the pesticide was then rinsed out with a solvent indicated in Table I for analysis. Some experiments were performed under a nitrogen gas stream in a box to eliminate the effect of air. The analytical method applied to each pesticide is listed in Table I.

\section{Isolation and characterization of photoproducts.}

The polar products of isoprothiolane $(R f=0.00$ and 0.08 in the solvent system A; see Table II) were extracted from the scraped silica gel of TLC with $50 \%$ methanol. The concentrates of the extract were submitted to TLC, PC, and HPLC for comparison with authentic compounds. For methylation the ether solution in which the scraped silica gel was immersed was treated with diazomethane prepared from $p$ toluenesulfonyl- $N$-methyl- $N$-nitrosamide and sodium hydroxide. The ether extract was concentrated and submitted to TLC or GC.

The less polar photoproducts $(3,4,5)$ were extracted with benzene and purified by repeating TLC and recrystallization from acetone except the product 5 . The purified products were submitted to spectrometries including UV, IR, NMR, and MS. The photoproducts of isoprothiolane homologs were similarly treated.

Chromatographies. Thin-layer chromatography (TLC): Precoated silica gel 60F-254 chromatoplates $(20 \times 20 \mathrm{~cm}, 0.25 \mathrm{~mm}$ layer thickness with fluorescent indicator, Merck) were used for analytical and preparative purposes and silica gel 60 chromatoplates without fluorescent indicator were used for photodegradation studies. Solvent systems (A to F) used for TLC are listed in Table II. Other solvent systems G (petroleum

Table I. Methods for Pesticide Determination

\begin{tabular}{|c|c|c|c|c|}
\hline \multirow{2}{*}{ Pesticide } & \multicolumn{3}{|c|}{ Analytical method } & \multirow{2}{*}{$\begin{array}{l}\text { Solvent for } \\
\text { rinse }\end{array}$} \\
\hline & Equipment & Solvent & Detector & \\
\hline Benthiocarb & $\mathrm{HPLC}^{a}$ & $95 \%$ ethanol & UV $254 \mathrm{~nm}$ & Ethanoì \\
\hline Carbaryl & $\mathrm{HPLC}^{\alpha}$ & $50 \%$ methanol & UV $280 \mathrm{~nm}$ & Ethanol \\
\hline Cartap & thinchrograph & $\begin{array}{l}\text { methanol-acetone- } \\
\text { benzene }=4: 1: 1\end{array}$ & FID & $50 \%$ ethanol \\
\hline Diazinon & $\mathrm{HPLC}^{a}$ & $50 \%$ methanol & UV $240 \mathrm{~nm}$ & Benzene \\
\hline IBP & $\mathrm{HPLC}^{a}$ & $50 \%$ methanol & UV $254 \mathrm{~nm}$ & Acetone \\
\hline \multirow[t]{2}{*}{ Isoprothiolane } & $\mathrm{GC}^{b}$ & & FPD $395 \mathrm{~nm}$ & Ethanol \\
\hline & UV spec. & $95 \%$ ethanol & $310 \mathrm{~nm}$ & Ethanol \\
\hline Mepronil & HPLC $^{a}$ & $95 \%$ ethanol & UV $254 \mathrm{~nm}$ & Benzene \\
\hline \multirow[t]{2}{*}{ Salithion } & $\mathrm{HPLC}^{\alpha}$ & $50 \%$ methanol & UV $270 \mathrm{~nm}$ & Acetone \\
\hline & $\mathrm{GC}^{e}$ & & FPD $395 \mathrm{~nm}$ & Acetone \\
\hline Thiram & $\mathrm{GC}^{d}$ & & FPD $395 \mathrm{~nm}$ & Chloroform \\
\hline
\end{tabular}

a ODS permaphase column. Rinsed solvent was evaporated and the residue was dissolved in ethanol to submit to HPLC.

b Glass column $(2.5 \mathrm{~m}) ; 5 \%$ silicone SE-30 on $80 / 100$ mesh Chromosorb WAW; $250^{\circ} \mathrm{C}$.

- Same column as $b ; 200^{\circ} \mathrm{C}$.

a Same column as $\mathrm{b} ; 130^{\circ} \mathrm{C}$. 
Table II. Chromatographic Data of Polar Photoproducts of Isoprothiolane

\begin{tabular}{|c|c|c|c|c|c|}
\hline Product No. & Assignment & & $\mathrm{LC}^{*}, R f$ & & $\mathrm{GC}, t_{R}(\mathrm{~min})$ \\
\hline 1a & $\begin{array}{l}\text { 1,3-dithiolan-2-ylidene- } \\
\text { malonic acid }\end{array}$ & $\begin{array}{c}0.00^{a} \\
(0.16)^{a}\end{array}$ & $0.61^{b}$ & $\begin{array}{c}0.78^{c} \\
(0.66)^{d}\end{array}$ & $(3.12)^{a}$ \\
\hline $1 b$ & oxalic acid & $0.00^{a}$ & & & $(1.85)^{h}$ \\
\hline $1 \mathrm{c}$ & unknown & $0.00^{a}$ & & & $(1.79)^{g}$ \\
\hline 2 & $\begin{array}{l}\text { 1,3-dithiolan-2-ylidene- } \\
\text { acetic acid }\end{array}$ & $0.08^{a}$ & $0.13^{e}$ & $0.90^{f}$ & $(1.15)^{q}$ \\
\hline
\end{tabular}

Parenthesis shows the data of methyl esters.

* Solvent systems for TLC are as follows: ${ }^{a} n$-hexane-benzene-acetone $=9: 5: 1$ (A); ${ }^{b}$ acetone-ethyl acetate-water $=13: 3: 1$ (B); ${ }^{c}$ ethyl acetate-acetic acid-water $=13: 3: 1(\mathrm{C}) ; d$ benzene-ethyl acetate $=$ $2: 1$ (D); ${ }^{6} n$-hexane-acetone-benzene $=9: 6: 2.3$ (E); ${ }^{f}$ acetone-acetic acid-water $=13: 3: 1$ (F).

- Glass column $(2.6 \mathrm{~m})$ packed with $5 \%$ silicone SE-30 on 80/100 mesh Chromosorb WAW, 250 C, FPD at $395 \mathrm{~nm}$.

h Same glass column as $\mathrm{g}, 100^{\circ} \mathrm{C}$, FID.

ether-ethyl acetate-acetone $=5: 1: 1)$ and $\mathrm{H}(n$-hexane-benzene-ethyl acetate $=10: 3: 2$ ) were also utilized to separate the photoproducts of the isoprothiolane homologs. The chromatograms were visualized by UV, iodine vapor, or $1 \%$ potassium permanganate.

Thinchrograph: An Iatroscan TFG-10 TLC analyzer equipped with a flame ionization detector and thinchromarods, i.e. silica gel-precoated quartz rods (Iatron Laboratories) were utilized for semi quantitative analytical purposes. Isoprothiolane products were developed by a solvent system ( $n$-hexane-benzene-acetone $=$ $8: 4: 1$ ). For cartap, see Table I.

Gas chromatography (GC): A JEOL JGC-750-1100 gas chromatograph equipped with a flame ionization detector and a Shimadzu GC-7A gas chromatograph equipped with a flame ionization detector were used. For the analysis of sulfur-containing pesticides, a flame photometric detector with a $394.5 \mathrm{~nm}$ filter was attached to the latter instrument.

High performance liquid chromatography (HPLC): A Shimadzu 830 high performance liquid chromatograph fitted with an ultra violet photometric detector was used for the analysis of pesticides and their photoproducts by utilizing an ODS Permaphase column. Ethanol $(95 \%)$ or $50 \%$ methanol was used as the mobile phase.

Spectrometries. A Shimadzu UV-200 double beam spectrophotometer was used for UV spectrometric measurements. Infrared absorption spectra were recorded on a Shimadzu IR-27G spectrophotometer with a grating. Proton and ${ }^{13} \mathrm{C}$ nuclear magnetic resonance spectra (NMR) were determined on a JEOL NMR spectrometer MH-100 and FX-100 (100 MHz) in appropriate deuterated solvents by using tetramethylsilane as an internal standard. Mass spectra were obtained with a JEOL mass spectrometer JMS-01 $\mathrm{SG}$ at $75 \mathrm{eV}$.

\section{RESULTS AND DISCUSSION}

\section{Photodegradation of isoprothiolane on silica gel plates}

When isoprothiolane placed on silica gel thin-layer plate was exposed to UV light (mainly $254 \mathrm{~nm}$ ), it decomposed rapidly. The half-life was approximately $3 \mathrm{hr}$. At that time, five spots of the photolysis products $1,2,3,4$ and 5 were detected at $R f 0.00,0.08,0.66$, 0.75 and 0.86 , respectively, besides unreacted isoprothiolane at $R f 0.44$ on TLC developed in the solvent system $A$. As will be described below, three products $1 \mathrm{a}, 1 \mathrm{~b}$ and $1 \mathrm{c}$ were found from TLC extract at $R f 0.00$.

Corresponding five peaks were observed on thinchrogram as shown in Fig. 1. The relative area ratios of the five peaks at the half-life time were $1.7,2.8,22.8,17.0$ and $5.7 \%$,

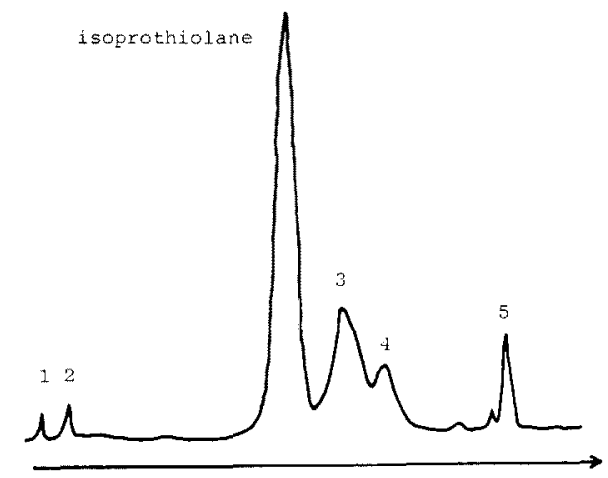

FIG. 1. Thinchrogram of Isoprothiolane Irradiated with Short Wave UV Light for $2.5 \mathrm{Hr}$. 


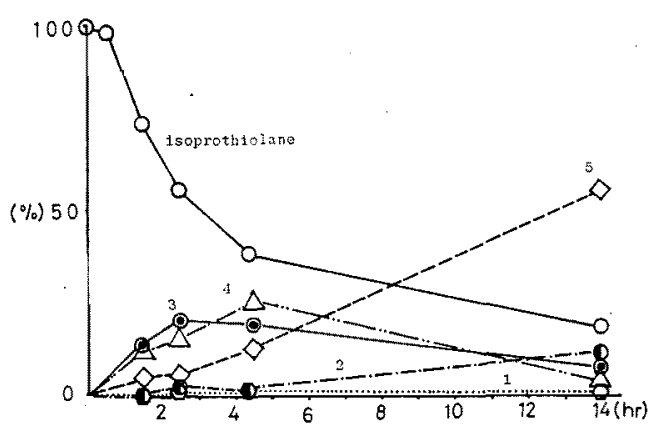

FIg. 2. Time Course of Isoprothiolane Photolysis on Silica Gel.

respectively. The peak 1 changed little in the area throughout the experiment, and the product 2 increased slightly. After the halflife time of isoprothiolane, the product 3 decreased gradually. Lagging somewhat behind this, the product 4 showed a similar tendency. The product 5 , however, increased with a lapse of irradiation time, reaching more than $50 \%$ after $14 \mathrm{hr}$ to become the major sole terminal product (Fig. 2).

On the other hand, long wavelength UV light $(>300 \mathrm{~nm})$ decomposed isoprothiolane slowly to give only two spots of the lowest $R f$ values $(0.00$ and 0.08$)$ even after $41 \mathrm{hr}$ irradiation. This was also the case when isoprothiolane was exposed to sunlight on silica gel for 9 days.

\section{Characterization of the photoproducts}

From the extract of TLC plate at $R f 0.00$, 1,3-dithiolan-2-ylidenemalonic acid (1a) was identified by comparison on TLC, PC and HPLC with authentic compounds directly or after methylation with diazomethane (Table II). From the same fraction of isoprothiolane photoproducts by the short wavelength UV light, oxalic acid (1b) was detected as the dimethyl ester by GC after treatment with diazomethane. Another unknown product 1c was detected after methylation on GC equipped with FPD for sulfur.

The photoproduct 2 of $R f 0.08$ was similarly identified as the hydrolyzed monodecarboxylated product, i.e. 1,3-dithiolan-2-ylideneacetic acid, by comparison with the authentic standard on TLC and GC (Table II).

The photoproduct 3 extracted from TLC plate at $R f 0.66$ was obtained as yellow needles, mp $130 \sim 131^{\circ} \mathrm{C}$. The proton NMR spectrum shown in Fig. 3 indicates it has isopropyl ester groups $[\delta 1.32(6 \mathrm{H}, \mathrm{d}), 5.22(1 \mathrm{H}, \mathrm{m})]$, but lacks the ethylene protons of the dithiolane ring at $\delta$ 3.41. Figure 4 shows the mass spectrum of the product 3 , which suggests it is the dimer of a dithiolane ring-cleaved product bearing the isopropyl ester groups: $m / e 460\left(\mathrm{M}^{+}\right), 418$ $\left(\mathrm{M}^{+}-\mathrm{C}_{3} \mathrm{H}_{6}\right), 401\left(\mathrm{M}^{+}-\mathrm{OC}_{3} \mathrm{H}_{7}\right), 374\left(\mathrm{M}^{+}-\right.$ $\left.\mathrm{CO}_{2} \mathrm{C}_{3} \mathrm{H}_{6}\right), 332\left(\mathrm{M}^{+}-\mathrm{C}_{3} \mathrm{H}_{6}-\mathrm{CO}_{2} \mathrm{C}_{3} \mathrm{H}_{6}\right), 288$

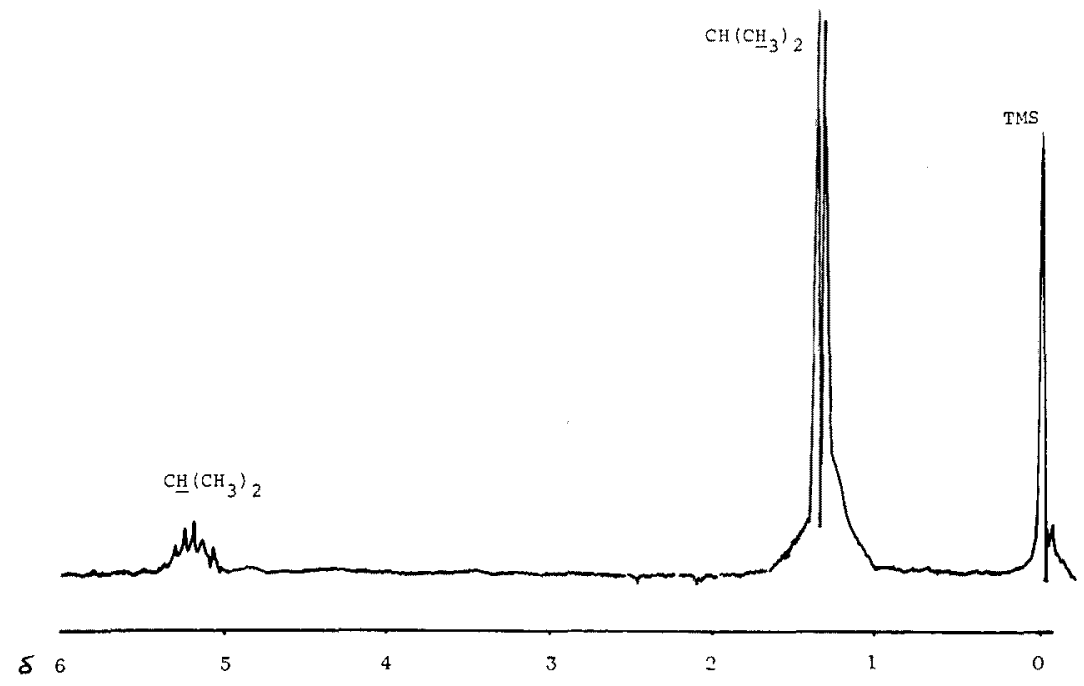

FIG. 3. Proton NMR Spectrum of Isoprothiolane Photoproduct $3(100 \mathrm{MHz})$. 


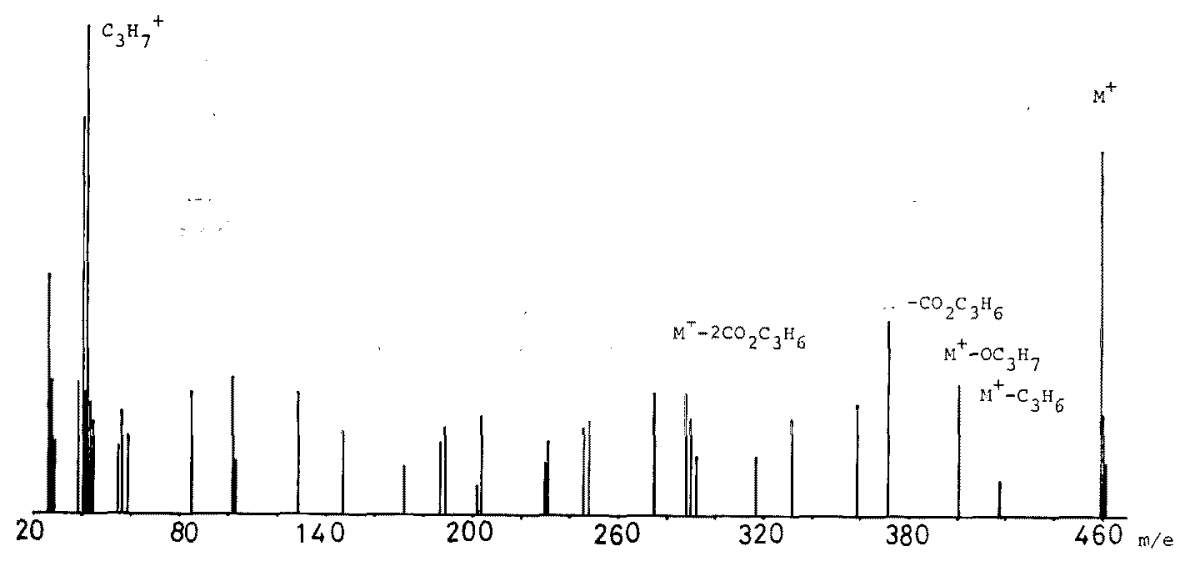

FIG. 4. Mass Spectrum of Isoprothiolane Photoproduct 3.

$\left(\mathrm{M}^{+}-2 \mathrm{CO}_{2} \mathrm{C}_{3} \mathrm{H}_{6}\right), 202\left(\mathrm{M}^{+}-3 \mathrm{CO}_{2} \mathrm{C}_{3} \mathrm{H}_{6}\right)$. The accurate mass measurement of the molecular ion at high resolution, 460.1149 , gives the molecular formula $\mathrm{C}_{20} \mathrm{H}_{28} \mathrm{O}_{8} \mathrm{~S}_{2}$ (calculated mass= 460.1226). As shown in Fig. 5A, the ester carbonyl stretching of the product 3 appears at considerably lower wave number $\left(1660 \mathrm{~cm}^{-1}\right)$ than that normally observed for simple $\alpha, \beta$ unsaturated esters $\left(1730 \sim 1717 \mathrm{~cm}^{-1}\right),{ }^{51}$ resembling that of isoprothiolane whose carbonyl stretching is at $1680 \mathrm{~cm}^{-1}$. Similar shift of carbonyl stretching to lower wave number has been reported in desaurins, ${ }^{6}$ ) i.e. 2,4-bis(acylmethylene)1,3-dithietanes, probably due to the interaction of sulfur atoms with the carbonyl groups through a conjugated $\pi$-electron system. ${ }^{71}$ The UV absorption spectrum of the product 3 was much different from isoprothiolane which has the maximum absorption at $307 \mathrm{~nm}$ (ethanol); UV $\lambda_{\max }^{\mathrm{EtOH}} \mathrm{nm}(\varepsilon)$ : $334(35,000), 345(36,000)$. The great shift of the maximum absorption to longer wavelength may be due to extension of the chromophoric system through sulfur atoms. All the evidence

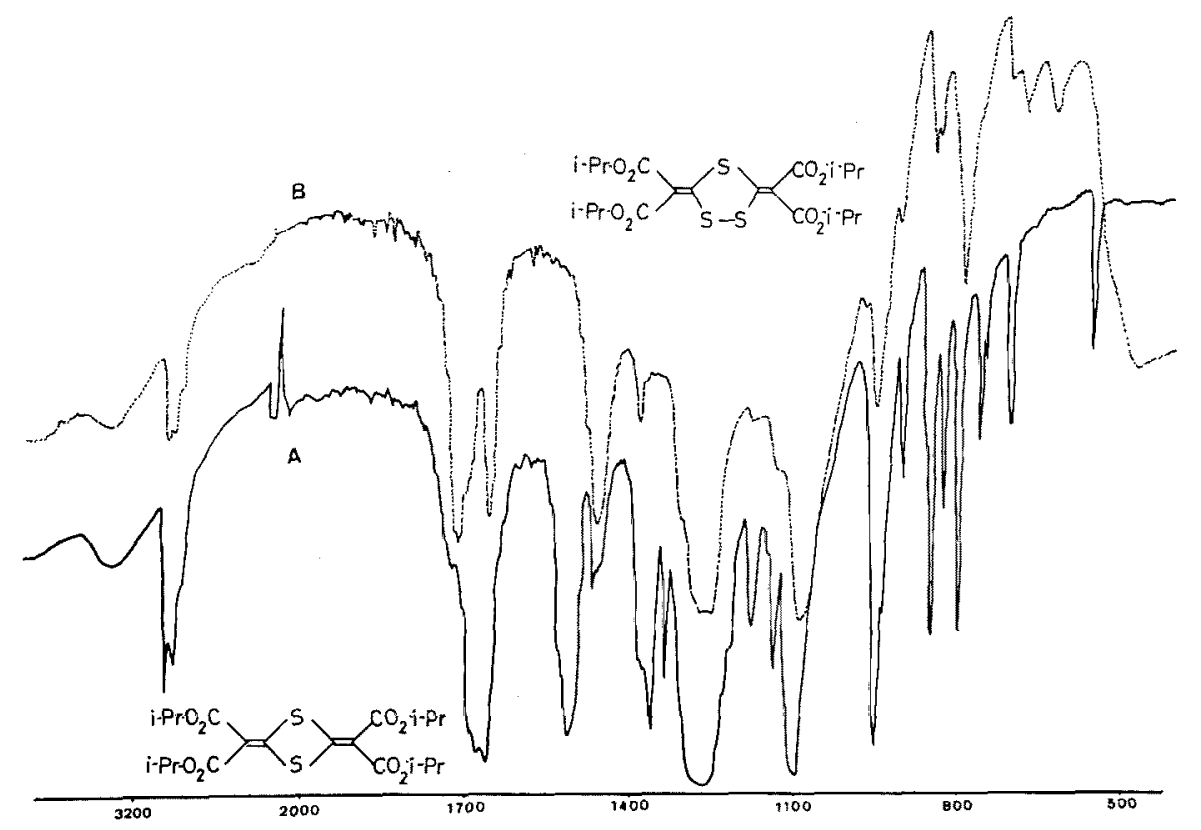

FIG. 5. IR Spectra of Isoprothiolane Photoproducts 3 (A) and 4 (B) (KBr). 
mentioned above supports the structure 3 ( $\mathrm{R}=i-\mathrm{C}_{3} \mathrm{H}_{7}$ ), that is 2,4-bis[bis(isopropoxycarbonyl)methylene]-1,3-dithietane. The ethyl homolog prepared from diethyl sodiomalonate and thiophosgene has been reported to show a similar IR spectrum; ; IR $\nu_{\max } \mathrm{cm}^{-1} 1511$, $1672,1689$.

The methyl homolog of isoprothiolane similarly gave the dithietane derivative $\left(3 ; \mathrm{R}=\mathrm{CH}_{3}\right.$ ) as a photoproduct by $\mathrm{UV}$ irradiation on silica gel layer, $m p 245^{\circ} \mathrm{C}$. Mass: $m / e 348\left(\mathrm{M}^{+}\right)$, $317\left(\mathrm{M}^{+}-\mathrm{OCH}_{3}\right), 290\left(\mathrm{M}^{+}-\mathrm{CO}_{2} \mathrm{CH}_{2}\right)$.

The photoproduct 4 of isoprothiolane at $R f 0.75$ was obtained as pale yellow cubes, mp $127 \sim 128^{\circ} \mathrm{C}$. Its proton NMR spectrum [ $\delta 1.32(6 \mathrm{H}, \mathrm{d}), 5.22(1 \mathrm{H}, \mathrm{m})]$ was essentially the same as that of the product 3 , indicating it had isopropyl ester groups but lacked the dithiolane ring. However, the IR spectrum of the product 4 presented in Fig. 5B differs from that of the product 3 (Fig. 5A), particularly in the carbonyl stretching region where two distinct bands at 1660 and $1715 \mathrm{~cm}^{-1}$ are observed. This suggests the product 4 has two kinds of ester groups whose environmental situation is different each other. Figure 6 shows the mass spectrum of the product 4 . The molecular ion at $m / e 492$ is bigger than that of the product 3 by 32 mass units, suggesting the product 4 is either the dioxygenated derivative or the trithio analog of the product 3 . The accurate mass of the molecular ion,
492.0903, was more consistent with the elemental composition of the trithio analog $\mathrm{C}_{20} \mathrm{H}_{28} \mathrm{O}_{8} \mathrm{~S}_{3}$ (calculated mass $=492.0946$ ) than that of the oxygenated derivative $\mathrm{C}_{20} \mathrm{H}_{28} \mathrm{O}_{10} \mathrm{~S}_{2}$ (calculated mass $=492.1124$ ). Thus, the most probable structure of the product 4 is 3,5 -bis[bis (isopropoxycarbonyl) methylene]-1, 2, 4-trithiolane $\left(4 ; \mathrm{R}=i-\mathrm{C}_{3} \mathrm{H}_{7}\right.$ ). The mass fragmentation pattern shown in Fig. 6 supports this structure: $m / e 492\left(\mathrm{M}^{+}\right), 460\left(\mathrm{M}^{+}-\mathrm{S}\right)$, $432\left(\mathrm{M}^{+}-\mathrm{C}_{3} \mathrm{H}_{7} \mathrm{OH}\right), 406\left(\mathrm{M}^{+}-\mathrm{CO}_{2} \mathrm{C}_{3} \mathrm{H}_{6}\right)$, $374\left(\mathrm{M}^{+}-\mathrm{S}-\mathrm{CO}_{2} \mathrm{C}_{3} \mathrm{H}_{6}\right)$.

The UV absorption maximum of the product 4 was longer in wavelength than that of isoprothiolane but shorter than that of the dithietan 3; UV $\lambda_{\max }^{\mathrm{EtOH}} \mathrm{nm}(\varepsilon): 330 \quad(27,000)$. This may be attributed to extension of the chromophoric system and to the ability of sulfur atoms for transmission of delocalization; the disulfide linkage is less effective than the sulfide linkage. Similar observation has been reported. ${ }^{9}$

The methyl and ethyl homologs of isoprothiolane similarly gave the corresponding trithiolane photoproducts by UV irradiation. The methyl homolog of product $4\left(\mathrm{R}=\mathrm{CH}_{3}\right)$, mp $200 \sim 201^{\circ} \mathrm{C}$, showed an appropriate mass spectrum: m/e $380\left(\mathrm{M}^{+}\right), 349\left(\mathrm{M}^{+}-\mathrm{OCH}_{3}\right)$, $348\left(\mathrm{M}^{+}-\mathrm{S}\right), 321\left(\mathrm{M}^{+}-\mathrm{CO}_{2} \mathrm{CH}_{3}\right)$. The ethyl homolog $\left(4 ; \mathrm{R}=\mathrm{C}_{2} \mathrm{H}_{5}\right)$ showed the following characteristics; $\mathrm{mp} 133 \sim 134^{\circ} \mathrm{C}$; NMR $\delta 1.40$ $(3 \mathrm{H}, \mathrm{t}), 4.43(2 \mathrm{H}, \mathrm{q}) ; \mathrm{IR} \nu_{\mathrm{max}}^{\mathrm{KBr}} \mathrm{cm}^{-1}: 1630$,

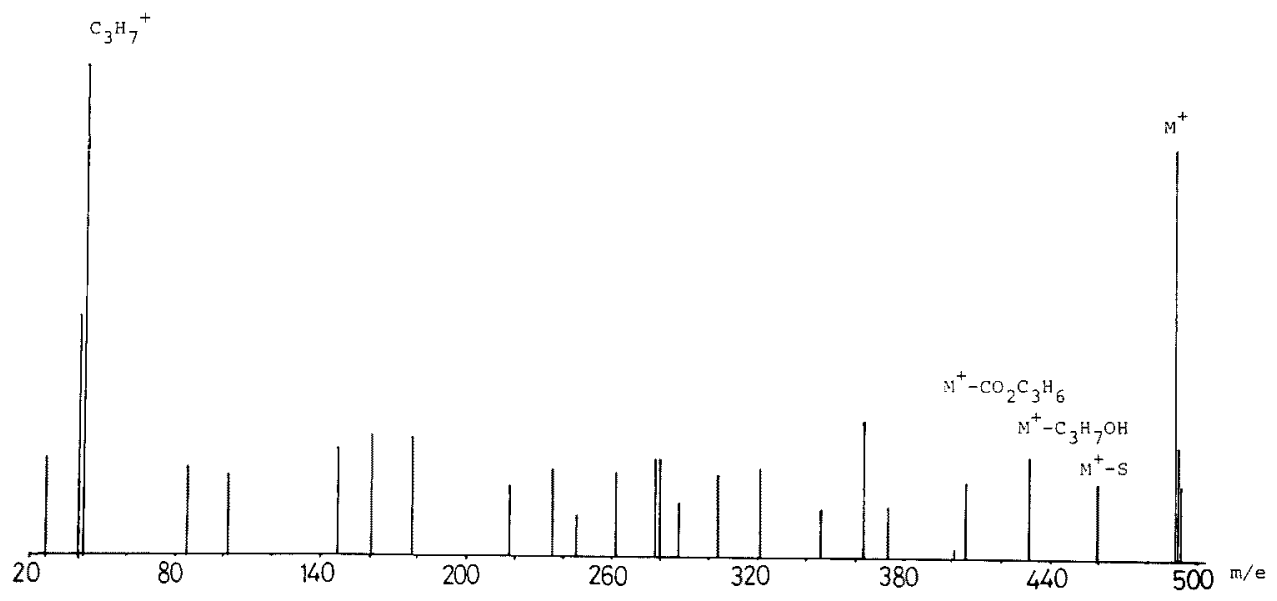

FiG. 6. Mass Spectrum of Isoprothiolane Photoproduct 4. 


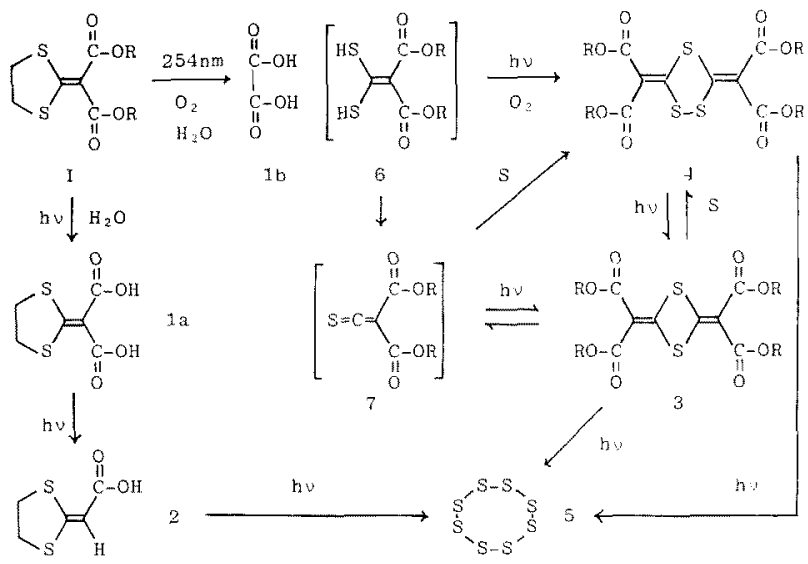

Scheme 1. Proposed Photolysis Pathways of Isoprothiolane $\left(\mathrm{I} ; \mathrm{R}=i-\mathrm{C}_{3} \mathrm{H}_{7}\right)$ and Its Homologs.

$1675(\mathrm{C}=\mathrm{O})$; Mass $m / e 436\left(\mathrm{M}^{+}\right), 404\left(\mathrm{M}^{+}-\mathrm{S}\right)$, $332\left(\mathrm{M}^{+}-\mathrm{S}-\mathrm{CO}_{2} \mathrm{C}_{2} \mathrm{H}_{4}\right)$.

Thus, the transformation of dithiolanylidenes into bismethylenedithietanes 3 and bismethylenetrithiolanes 4 occurs commonly by the irradiation of short wavelength UV light.

The isoprothiolane photoproduct 5 at $R f$ 0.86 was obtained as yellow crystals, $\mathrm{mp} 117 \sim$ $118^{\circ} \mathrm{C}$. It did not give any significant proton NMR signals, but a molecular ion peak at $m / e 256$ which was accompanied by the large peaks of $\mathrm{M}+2(38.2 \%)$ and $\mathrm{M}+4(5.8 \%)$. This indicates the product 5 is $\mathrm{S}_{8}$ whose calculated isotope contributions to the $\mathrm{M}+2$ and $\mathrm{M}+4$ peaks are 35.2 and $5.6 \%$, respectively. This is also supported by the characteristic mass fragmentation pattern in which the ion peaks are apart by 32 mass units (S): $m / e$ 256, 224, 192, 160, 128, 96, 64 .

\section{Pathways of isoprothiolane photolysis}

The degradation pathways of isoprothiolane exposed to short wavelength UV light in air appear to be divided into two different types; 1) the degradation of the ester groups and 2) the cleavage of dithiolane ring followed by recombination to dithietane and trithiolane.

On UV irradiation, the photoproduct 1a, dithiolanylidenemalonic acid, gave the monodecarboxylated product 2 and sulfur, whereas the product 2 gave sulfur. On the other hand, the product 3 and 4 , i.e. the dithietane and the trithiolane derivatives, were interconvertible
Table III. Effects of Surface and Air on Pesticide Photolysis

\begin{tabular}{|c|c|c|c|c|}
\hline \multirow{2}{*}{ Pesticide } & \multirow{2}{*}{$\begin{array}{l}\text { UV } \\
\text { exposure } \\
\text { time } \\
\text { (hr) }\end{array}$} & \multicolumn{3}{|c|}{ Decomposition $(\%)$ on } \\
\hline & & $\begin{array}{l}\text { Glass } \\
\text { plate }\end{array}$ & $\begin{array}{l}\text { Sand } \\
10 / 15 \\
\text { mesh }\end{array}$ & $\begin{array}{l}\text { Sand } \\
20 / 30 \\
\text { mesh }\end{array}$ \\
\hline Benthiocarb & 5 & 49.8 & 59.8 & 65.4 \\
\hline Carbaryl & 5 & 9.2 & 20.0 & 21.7 \\
\hline Cartap & 2.5 & 39.5 & 82.7 & 90.8 \\
\hline Diazinon & 5 & 34.4 & 54.8 & \\
\hline IBP & 5 & 25.2 & 40.6 & 50.8 \\
\hline \multirow[t]{2}{*}{ Isoprothiolane } & 2.5 & 50.6 & 65.6 & 75.3 \\
\hline & 2.5 in $\mathrm{N}_{2}$ & 31.6 & 38.2 & 41.8 \\
\hline Mepronil & 5 & 2.5 & 2.0 & 0 \\
\hline \multirow[t]{2}{*}{ Salithion } & 5 & 17.0 & 26.2 & 25.9 \\
\hline & 5 in $\mathrm{N}_{2}$ & 12.8 & 18.2 & 18.2 \\
\hline \multirow[t]{2}{*}{ Thiram } & 3 & 37.5 & 55.0 & 72.5 \\
\hline & 3 in $N_{2}$ & 31.3 & 30.8 & 52.1 \\
\hline
\end{tabular}

besides producing sulfur by UV irradiation.

When isoprothiolane was exposed to UV light under nitrogen atmosphere, the photolysis rate decreased remarkably (Table III). The UV spectrum of the reaction mixture changed only in the maximum absorbance without shift in wavelength $(307 \mathrm{~nm})$, indicating neither the dithietane $\left(\lambda_{\max }: 334\right.$ and $\left.344 \mathrm{~nm}\right)$ nor the trithiolane $\left(\lambda_{\max }: 330 \mathrm{~nm}\right)$ was produced. This was confirmed by TLC analysis, which showed only the formation of diethiolanylidenemalonic acid and dithiolanylideneacetic acid. In air UV irradiation caused the considerable shift of the maximum absorption of the reaction mixture to longer wavelength owing to the transformation of the dithiolane to the di- 
thietane and the trithiolane. This and the finding of oxalic acid as the photolysis product indicate that oxygen participates to the photolytic cleavage of dithiolane ring. On the other hand, the degradation of the ester group appears to require no oxygen (but water for hydrolysis).

The possible intermediates to produce the dithietane and the trithiolane may be the dithioic acid (thioenol type) 6 and/or the thioketene 7. It has been known that trithiolanes are produced by the oxidation of dithioic acids $^{9,10}$ and the reaction of thioketenes with sulfur. ${ }^{8}$ ) Thioketenes are known to dimerize easily to form dithietanes, which can back to monomeric thioketenes by heat. ${ }^{8)}$ A reaction between dithioic acids and thioketenes has been proposed as a probable pathway to produce dithietanes by the reaction of active methylene compounds with carbon disulfide in the presence of bases. ${ }^{11}$ ) The transformation of a trithiolane into a dithietane by the action of alkali is known. ${ }^{9}$ Similar reactions may occur to be induced by UV irradiation. On these chemical relationships the photolytic pathways of isoprothiolane and related compounds under short wavelength UV are proposed as shown in Scheme 1. The photoactivation of the charge-transfer oxygenisoprothiolane complex at sulfur atoms may be the initiation step of $\mathrm{S}-\mathrm{C}_{\alpha}$ bond cleavage. On exposure to sun-light, however, the transformation of the dithiolane ring did not occur, but the decarboxylation did probably owing to $n \pi^{*}$ excitation $(\lambda=307 \mathrm{~nm})$. The low energy of sun-light $(>290 \mathrm{~nm})$ appears to be not enough for the excitation of the charge-transfer complex to cause the cleavage of the hetero ring.

Effects of solid surface on the photolysis of some pesticides

The photolysis rate of isoprothiolane was greatly affected by solid surface where it was deposited. As shown in Fig. 7, it was much more rapidly decomposed on sea sand than on glass plate. The less in particle size of sand, in other words the more in the area of

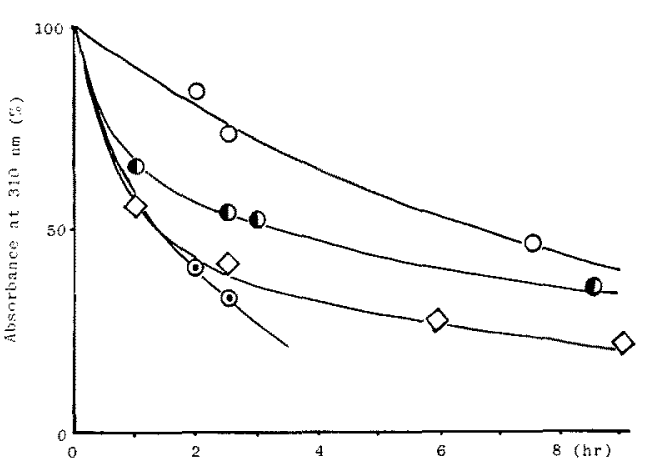

FIG. 7. Effect of Solid Surface on Isoprothiolane Photolysis.

$\bigcirc$, glass plate; $0,10 / 15$ mesh sand; $\diamond, 20 / 30$ mesh sand; $\odot,>30$ mesh sand.

surface, the more rapid the degradation rate. This surface effect was greatly depressed under nitrogen atmosphere (Table III). The similar phenomenon was more or less observed in the photolysis of some other pesticides. It is interesting to note that the surface effect appears particularly on cartap, thiram and other sulfurcontaining compounds in contrast with nonsulfur-containing compounds such as mepronil as shown in Table III.

It has been reported that certain pesticides undergo photodegradation more rapidly on the surface of soil or silica gel than in water. ${ }^{12}$ ) Such an effect of particle surface could be attributed sometimes to the shift of UV absorption spectrum by an interaction between the substrate and the absorbent as a possible reason. ${ }^{13)}$ However, in the case that the surface effect is depressed under nitrogen atmosphere as exemplified by isoprothiolane, the effect may be at least in part due to the arrangement of area where an interaction between the substrate and oxygen molecules (or water sometime) takes place. Sulfur-containing pesticides may have high tendency to be decomposed photooxidatively. The catalytic nature of soil as solid particles is very important from the environmental point of view for the photolysis of pesticides.

Acknowledgments. This work was supported in part by Grant-in-Aid for Environmental Science to M.E. from the Ministry of Education, Science and Cul- 
ture, Japan. Thanks are also due to some companies described in the text for supplying the chemicals.

\section{REFERENCES}

1) T. Tsumura, Jap. Pestic. Inform., 27, 20 (1976).

2) T. Sugimoto, F. Araki and K. Taninaka, $J$. Pestic. Sci., 2, (Sp. Iss.), 505 (1977).

3) M. Eto, S.-S. Chou and E. Taniguchi, ibid., 4, 379 (1979).

4) S.-S. Chou and M. Eto, J. Environ. Sci. Health, B15, 135 (1980).

5) L. J. Bellamy, "The Infra-red Spectra of Complex Molecules," Methuen, London, 1958, p. 179.
6) V. Meyer, Ber., 23, 1571 (1890).

7) P. Yates, T. R. Lynch and D. R. Moore, Can. $J$. Chem., 49, 1467 (1971).

8) M. S. Raasch, J. Org. Chem., 35, 3470 (1970).

9) P. Yates and T. R. Lynch, Can. J. Chem., 49, 1477 (1971).

10) G. Wenzel, Ber., 34, 1043 (1901).

11) P. Yates, D. R. Moore and T. R. Lynch, Can. J. Chem., 49, 1456 (1971).

12) N. Mikami, H. Ohkawa and J. Miyamoto, J. Pestic. Sci., 1, 273 (1976).

13) J. R. Plimmer, "Pesticide Chemistry," Vol. VI, ed. by A. S. Tahori, Gordon and Breach Science Pub., London, 1972, p. 47. 